\title{
Oxidative Stress in Alzheimer's Disease: In Vitro Therapeutic Effect of Amniotic Fluid Stem Cells Extracellular Vesicles
}

\author{
Martina Gatti $\left(\mathbb{D},{ }^{1}\right.$ Manuela Zavatti $\mathbb{D}^{1},{ }^{1}$ Francesca Beretti $\left(\mathbb{D},{ }^{1}\right.$ Daniela Giuliani $(D),{ }^{1}$ \\ Eleonora Vandini $\mathbb{D}^{1},{ }^{1}$ Alessandra Ottani $\mathbb{D}^{1},{ }^{1}$ Emma Bertucci $\mathbb{D},{ }^{2}$ and Tullia Maraldi $\mathbb{D}^{1}$ \\ ${ }^{1}$ Department of Biomedical, Metabolic and Neural Sciences, University of Modena and Reggio Emilia, Modena 41125, Italy \\ ${ }^{2}$ Department of Medical and Surgical Sciences for Mothers, Children and Adults, University of Modena and Reggio Emilia, \\ Azienda Ospedaliero Universitaria Policlinico, Via Del Pozzo 71, 41124 Modena, Italy
}

Correspondence should be addressed to Tullia Maraldi; tullia.maraldi@unimore.it

Received 27 May 2020; Revised 20 July 2020; Accepted 31 July 2020; Published 24 October 2020

Guest Editor: Raquel Rodriguez-Diez

Copyright (C) 2020 Martina Gatti et al. This is an open access article distributed under the Creative Commons Attribution License, which permits unrestricted use, distribution, and reproduction in any medium, provided the original work is properly cited.

\begin{abstract}
Alzheimer's disease (AD) is characterized by abnormal protein aggregation, deposition of extracellular $\beta$-amyloid proteins (A $\beta$ ), besides an increase of oxidative stress. Amniotic fluid stem cells (AFSCs) should have a therapeutic potential for neurodegenerative disorders, mainly through a paracrine effect mediated by extracellular vesicles (EV). Here, we examined the effect of EV derived from human AFSCs (AFSC-EV) on the disease phenotypes in an AD neuron primary culture. We observed a positive effect of AFSC-EV on neuron morphology, viability, and $\mathrm{A} \beta$ and phospho-Tau levels. This could be due to the apoptotic and autophagic pathway modulation derived from the decrease in oxidative stress. Indeed, reactive oxygen species (ROS) were reduced, while GSH levels were enhanced. This modulation could be ascribed to the presence of ROS regulating enzymes, such as SOD1 present into the AFSC-EV themselves. This study describes the ROS-modulating effects of extracellular vesicles alone, apart from their deriving stem cell, in an $\mathrm{AD}$ in vitro model, proposing AFSC-EV as a therapeutic tool to stop the progression of $\mathrm{AD}$.
\end{abstract}

\section{Introduction}

Neurodegenerative diseases are characterized by progressive damage in neural cells which leads to compromised motor or cognitive functions. Alzheimer's disease $(\mathrm{AD})$ is the sixth leading cause of death in the United States, and it is the most widespread neurodegenerative disorder, which significantly affects people's daily lives [1]. The pathophysiology of $\mathrm{AD}$ is mainly associated with the extracellular deposition of amyloid beta $(\mathrm{A} \beta)$ plaques and the accumulation of intracellular tau neurofibrillary tangles (NFT) [2]. The mechanisms behind $\mathrm{A} \beta$ neurotoxic action could be several; many of which flow into the reactive oxygen species (ROS) generation. For example, $\mathrm{A} \beta$ plaques can reduce calcium ion storage in endoplasmic reticulum, then resulting in cytosolic $\mathrm{Ca}^{2+}$ overload. As a consequence of cytosolic $\mathrm{Ca}^{2+}$ increase, endogenous glutathione (GSH) levels are reduced and ROS are overaccumulated inside the cells [3]. In addition, $A \beta$ proteins can directly cause free radical formation via the activation of NADPH oxidase [4]. Indeed, ROS are chemically reactive molecules that are involved in the pathogenesis of neurodegenerative diseases. Although it is not yet understood whether ROS could be the triggering factor in neurodegenerative diseases, they probably are to be considered exacerbating players in the disease progression through oxidative damage $[5,6]$. Of note is that neuronal cells are particularly vulnerable to oxidative damage because of their high polyunsaturated fatty acid content in membranes, high oxygen consumption, and weak antioxidant defense [7].

Moreover, ROS can regulate JNK/stress-activated protein kinase pathways. The activation of these cascades is linked to the hyperphosphorylation of tau proteins and $A \beta$-induced cell death [8]. The pathogenesis of several neurodegenerative disorders, such as AD and Parkinson's disease, is associated with the accumulation of misfolded proteins. Inflammatory response in the brain can be activated to counteract the 
aggregation of these modified proteins, while inducing a marked ROS release and subsequent oxidative stress (OS) $[9,10]$. Therefore, a vicious circle, in which the ROS level increases, seems to be triggered. Considering the pivotal roles of OS in neurodegenerative diseases, the regulation of ROS levels could be a promising target to slow down neurodegeneration and alleviate associated symptoms. However, most of the antioxidants which have been studied, proved scarcely successful in clinical trials, which may be due to their scarce distribution and inherent difficulties to cross the blood brain barrier and reach the target sites. Despite the evidence that different classes of antioxidants are neuroprotectants in vitro, the clinical data is not consistent [11]. Based on these considerations, finding a way to combine neuroprotective, anti-inflammatory, and endogenous antioxidant manipulation properties may hold great promise to counteract $\mathrm{AD}$ symptoms.

Mesenchymal stem cells (MSCs) and, in particular, MSCderived extracellular vesicles (EV), could be proposed as a strategic approach to contrast this pathology. Indeed, MSCEV_carrying lipids/proteins/enzymes/microRNAs endowed with anti-inflammatory, $\mathrm{A} \beta$ degrading systems, and neurotrophic activities [12] — could be the therapeutic tool combining different properties able to restore the synaptic function, prevent neuronal death, and slow down memory impairment in $\mathrm{AD}$.

Several demonstrations of the effect of MSC-EV on lowering $\mathrm{AD}$ markers are present in the literature on the in vitro AD cell models. The exposure to MSC-EV was first investigated in a cellular model of $\mathrm{AD}$ by using EVs isolated from adipose tissue MSCs. The incubation of MSC-EVs to N2A neuroblastoma cells reduced both secreted and intracellular A $\beta$ peptide levels [13]. Similarly, more recently MSC transwell coculture with rat neurons exposed to soluble oligomers of the $\mathrm{A} \beta$ peptide $(\mathrm{A} \beta \mathrm{O}$ ) ) induced internalization and degradation of $\mathrm{A} \beta \mathrm{O}$ s, release of extracellular vesicles containing active catalase, and selective secretion of interleukin-6, interleukin-10, and vascular endothelial growth factor to the medium [14].

Amniotic fluid stem cells (AFSCs) are a feasible variety of MSC for experimentation purposes, owing to their pluri/multipotency, abundance, and minimal ethical considerations. We recently reported that AFSC secretory factors have antiapoptotic and anti-inflammatory effects $[15,16]$. Although the paracrine function of stem cells is reported to have a therapeutic potential in many neurological disorders, the effects of AFSC-derived extracellular vesicles (AFSC-EV) on the cellular phenotypes of $\mathrm{AD}$ have not yet been investigated. A primary culture of neurons, derived from $5 x F A D$ mice $[17,18]$, an animal model of $\mathrm{AD}$, was here employed to investigate the effect of an enrichment in extracellular vesicles obtained from human AFSCs on morphological features, apoptosis/viability parameters, and $\mathrm{AD}$ markers. We focused our attention on the EV-modulation of ROS levels as pivotal key to counteract neurodegenerative diseases.

\section{Materials and Methods}

2.1. Amniotic Fluid Collection. The AFSCs were obtained from amniotic fluids collected from 4 healthy pregnant women at the 16th week of gestation who underwent amnio- centesis for maternal request (not for foetal anomalies) at the Unit of Obstetrics \& Gynecology, IRCCS-ASMN of Reggio Emilia and at the Policlinico Hospital of Modena (Italy). The amniocentesis was performed under continuous ultrasound guidance, in a sterile field, with 23-Gauge needles. The risks related to the procedure and the purpose of the study were explained to all patients before the invasive procedure and the ob-gyn specialist collected a signed consent before starting the exam (protocol 2015/0004362 of 02.24.2015 and protocol 360/2017 dated 12.15.2017 approved by Area Vasta Emilia Nord). For this study, supernumerary (unused) flask of AF cells, cultured in the Laboratory of Genetics of TEST Lab (Modena, Italy) for 2 weeks, was used.

2.2. Adult Human Tissue Isolation and Cell Culture. AFSCs were isolated as previously described [19]. Human amniocentesis cultures were harvested by trypsinization and subjected to c-kit immunoselection by MACS technology (Miltenyi Biotec, Germany). AFSCs were subcultured routinely at 1:3 dilution and not allowed to grow beyond the $70 \%$ of confluence. AFSCs were grown in culture medium ( $\alpha$ MEM) supplemented with $20 \%$ fetal bovine serum (FBS), $2 \mathrm{mM}$ L-glutamine, $100 \mathrm{U} / \mathrm{ml}$ penicillin, and $100 \mu \mathrm{g} / \mathrm{ml}$ streptomycin (all from EuroClone Spa, Milano, Italy).

2.3. Extracellular Vesicle Isolation from Conditioned Medium. AFSCs were grown in $75 \mathrm{~cm}^{2}$ flask until subconfluence (around $1 \times 10^{6}$ cells). Before extracellular vesicle extraction, the cells were maintained for 4 days in $10 \mathrm{~mL}$ culture medium deprived of FBS in order to exclude the contamination by extracellular vesicles comprised into FBS solution. The secreted part of conditioned medium (CM) was then concentrated up to $2 \mathrm{~mL}$ by using centrifugal filter units with $3 \mathrm{~K}$ cutoff [15]. Then, the concentrated CM was treated with total exosome isolation solution from cell culture media (Invitrogen, Life Technologies, CA. USA), according to the manufacturer's instructions. The pellet, enriched in exosomes although it can be not a pure extraction, was collected and quantified by the Bradford method. To obtain a sample for Western blot analysis, the pellet was resuspended in lysis buffer. We previously showed morphological characterization of extracellular vesicles by electron microscopy [15].

The surnatants deriving from the isolation protocol (-EV) were collected as well. The neuroblastoma cell line SH-SY 5Y, cultured in 1:1 DMEM (EuroClone Spa, Milano, Italy)/F12 (EuroClone Spa, Milano, Italy), 1\% fetal bovine serum (FBS) (Microgem, Naples, Italy), $2 \mathrm{mM}$ glutamine, $100 \mathrm{U} / \mathrm{ml}$ penicillin and $100 \mu \mathrm{g} / \mathrm{ml}$ streptomycin, $1 \mathrm{mM}$ Not-Essential Amino Acids (all from EuroClone Spa, Milano, Italy), was exposed to $10 \mu \mathrm{M} \mathrm{A} \beta$ 1-42 (Anaspec Inc., California, USA) for $24 \mathrm{~h}$ in order to test $\mathrm{EV}$ and $-\mathrm{EV}$ in a simple $\mathrm{AD}$ in vitro model. The same protein concentration of $+\mathrm{EV}$ and $-\mathrm{EV}$ was added to neuronal cells 3 days before $\mathrm{A} \beta$ treatment.

2.4. Animals. $5 x F A D$ mice cooverexpress a triple-mutant human amyloid precursor protein (APP) (Swedish mutation: K670N, M671L; Florida mutation: I716V; London mutation: 
V717I) and a double-mutant human presenilin 1 (PS1) (M146L and L286V mutations) transgenes under the transcriptional control of the neuron specific Thy-1 promotor. Progenitors were purchased from Jackson Laboratories, Bar Harbor, and $5 \mathrm{xFAD}$ line was maintained by crossing hemizygous $5 \mathrm{xFAD}$ mice with $\mathrm{B} 6 \mathrm{SJL} / \mathrm{J}$ breeder. Mice were kept in conditioned rooms with stable temperature $\left(22 \pm 1^{\circ} \mathrm{C}\right)$ and humidity (60\%), on a light/dark cycle of 12 hours, with food and water ad libitum. All animal procedures were approved by the Committee on Animal Health and Care of the University of Modena and Reggio Emilia (protocol number: 974/2016-PR del 13-10-2016) and conducted in accordance with National Institutes of Health guidelines.

For genotyping procedure, APP and PS1 lines were analyzed as previously reported (Gordon et al. 2001). Tail samples from WT and 5xFAD mice were examined by using primers supplied by Jackson Laboratories to identify either the mutation or the wild-type allele with the polymerase chain reaction (PCR): forward, $5^{\prime}$-AGGACTGACCACTCGACCAG-3' and reverse, $5^{\prime}$-CGGGGGTCT AGTTCTGCAT-3' for APP transgenes; forward, $5^{\prime}$-CTAGGCCACAGAATTGAAAGATCT- $3^{\prime}$ and reverse $5^{\prime}$-GTAGGTGGAAATTCTAGCATCA-TCC- $3^{\prime}$ for positive control; forward, $5^{\prime}$-AAT AGA GAA CGG CAG GAG CA- $3^{\prime}$ and reverse $5^{\prime}$-GCC ATG AGG GCA CTA ATC AT- $3^{\prime}$ for hPRES transgene. DNA was polymerized at $94^{\circ} \mathrm{C}$ for $3 \mathrm{~min} ; 35$ cycles of $94^{\circ} \mathrm{C}$ for $15 \mathrm{~s} ; 54^{\circ} \mathrm{C}$ for $1 \mathrm{~min}$; $72^{\circ} \mathrm{C}$ for $1 \mathrm{~min}$; and $72^{\circ} \mathrm{C}$ for $2 \mathrm{~min}$; stored at $4^{\circ} \mathrm{C}$. The PCR products were run on a $1 \%$ agarose gel, using ethidium bromide ultraviolet (UV) detection for the bands at $377 \mathrm{bp}$ (APP transgene) or $324 \mathrm{bp}$ (positive control) and $608 \mathrm{bp}$ (hPRES).

\subsection{Preparation of Primary Cultured Cortical Neurons. Cor-} tical and hippocampal neurons from wild type (WT) $(N=18)$ and $5 x F A D(F A D)(N=25)$ mice were collected within $24 \mathrm{~h}$ from birth [20]. Brains were removed, meninges were gently peel off, and cortical and hippocampal tissue dissected. Tissues were incubated in a buffer solution containing HBSS (Hanks' Balanced Salt Solution, GIBCO, Milan, Italy) with BSA $0.3 \%$ (Microgem Srl, Naples, Italy) and trypsin $0.025 \%$ (EuroClone, Milan, Italy) at $37^{\circ} \mathrm{C}$ for $15 \mathrm{~min}$. Then, tissues were triturated with a plastic $1000 \mu \mathrm{l}$ pipette tip in a HBSS buffer containing 0.004\% deoxyribonuclease I (DNAseI, Sigma Aldrich) and 10\% fetal bovine serum (FBS, Microgem Srl). After centrifugation at $500 \mathrm{~g}$ for $5 \mathrm{~min}$, cells were suspended in Neurobasal medium supplemented with $2 \%$ B27 (GIBCO, Thermo Fisher Scientific, Monza, Italy), $2 \mathrm{mM}$ glutamine, $100 \mathrm{U} / \mathrm{ml}$ penicillin and, $100 \mu \mathrm{g} / \mathrm{ml}$ streptomycin (EuroClone) and plated on poly-L-lysine (Merck Millipore, Milan, Italy) coated plastic or coverslips at 0.5 $\times 10^{6} \mathrm{cells} / \mathrm{cm}^{2}$. Cells were maintained at $37^{\circ} \mathrm{C}$ and $5 \% \mathrm{CO}_{2}$. After $48 \mathrm{~h}$, cells were treated with $5 \mu \mathrm{M}$ cytosine $\beta$-D-arabinofuranoside (Sigma Aldrich) for $24 \mathrm{~h}$.

For in vitro experiments, $10 \mu \mathrm{g}$ of extracellular vesicles, obtained from the two human samples of AFSCs, resuspended in PBS, were added to $1 \times 10^{6}$ cells at DIV (days in vitro) 3 for 7 up to 14 days.

Wortmannin (Sigma Aldrich) treatment was performed for $2 \mathrm{~h}$ prior the EV exposure.
2.6. Cellular Morphology. Cellular images were acquired using EVOS XL Core Cell Imaging System (Thermo Fisher Scientific, Vantaa, Finland). Parameter and area were measured with ImageJ using image pixels as scale. Cellular elongation was calculated using the following formula:

$$
\text { Cellular elongation }=\mathrm{p} 2 / 4 \pi * \mathrm{~A}
$$

where $p$ is the cellular perimeter, $\pi$ is equivalent to 3.14 , and $A$ represents the cellular area.

2.7. MTT Assay. Primary neurons were seeded in 96-well plates in $200 \mu \mathrm{l}$ of a culture medium, 4 replicates for each condition. At the end of each experiment, $0.5 \mathrm{mg} / \mathrm{ml} \mathrm{MTT}$ was added and incubated for $3 \mathrm{~h}$ at $37^{\circ} \mathrm{C}$. After incubation, the medium was removed and acidified isopropanol was added to solubilize the formazan salts [21]. The absorbance was measured at $570 \mathrm{~nm}$ using a microplate spectrophotometer (Appliskan, Thermo-Fisher Scientific, Vantaa, Finland).

2.8. ROS and Glutathione Detection. To evaluate intracellular ROS levels, dichlorodihydrofluorescein diacetate (DCFHDA) assay was performed similarly to as previously described [22]. Cells were seeded in a black 96-well plate, 4 replicates for each condition. Cell culture medium was removed, and the $5 \mu \mathrm{M}$ DCFH-DA was incubated in PBS for $30 \mathrm{~min}$, at $37^{\circ} \mathrm{C}$ and $5 \% \mathrm{CO}_{2}$. The cell culture plate was washed with PBS, and fluorescence of the cells was read at $485 \mathrm{~nm}$ (excitation) and $535 \mathrm{~nm}$ (emission) using the multiwall reader Appliskan (Thermo-Fisher Scientific, Vantaa, Finland). Cellular autofluorescence was subtracted as a background using the values of the wells not incubated with the probe.

Similarly, to evaluate reduced GSH levels, monochlorobimane $(\mathrm{MCB})$ assay was performed as previously reported [23]. Cell culture medium was removed, and $50 \mu \mathrm{M} \mathrm{MCB}$ was incubated in $\mathrm{PBS}$ for $30 \mathrm{~min}$, at $37^{\circ} \mathrm{C}$ and $5 \% \mathrm{CO}_{2}$. The cells were washed in PBS, and fluorescence of the cells was measured at $355 \mathrm{~nm}$ (excitation) and $460 \mathrm{~nm}$ (emission).

2.9. Quantification of $A \beta$ by ELISA. Secreted amyloid beta peptide1-42 (A $\beta 42)$ from primary cultured neurons was analyzed in medium exposed to neurons by BETA-APP42 ELISA Kit (Human) (Aviva Systems Biology, San Diego, CA, USA).

Medium from $5 \mathrm{xFAD}$ cells treated with AFSC-EV for 7 days and control were collected and then centrifuged at $20^{\circ} \mathrm{C} 1200 \mathrm{rpm}$ for 10 minutes in order to remove cellular debris.

Supernatants were concentrated about 10 times by lyophilization with LIO5P (5Pascal, MI, Italy) (Sun et al. 2014). Freeze-dried powder obtained from $6 \mathrm{ml}$ of medium exposed to neurons was rehydrated with $600 \mu \mathrm{l}$ of purified water and stored at $+4^{\circ} \mathrm{C}$ until test. Concentrated media were used for the ELISA assay.

A $\beta$ ELISA was performed according to the manufacturer's protocol of ELISA kit (Aviva Systems Biology, San Diego, CA, USA).

2.10. Cellular Extracts Preparation. Cell extracts were obtained as previously described [24]. Briefly, subconfluent 
cells were extracted by addition of lysis buffer $(20 \mathrm{mM}$ TrisCl, pH 7.0; 1\% Nonidet P-40; 150 mM NaCl; $10 \%$ glycerol; $10 \mathrm{mM}$ EDTA; $20 \mathrm{mM} \mathrm{NaF} ; 5 \mathrm{mM}$ sodium pyrophosphate; and $1 \mathrm{mM} \mathrm{Na}_{3} \mathrm{VO}_{4}$ ) and freshly added Sigma Aldrich Protease Inhibitor Cocktail and para-Nitrophenylphosphate (pNPP) at $4^{\circ} \mathrm{C}$ for $20 \mathrm{~min}$. Lysates were sonicated, cleared by centrifugation, and immediately boiled in SDS reducing sample buffer.

2.11. SDS PAGE and Western Blot. Whole cell lysates from primary neurons and AFSC-EV were processed as previously described [25]. Primary antibodies were raised against the following molecules: Actin, Nox4 (Sigma-Aldrich, St Louis, MO, USA), Akt, SOD1, SIRT1, gp91phox, TrxR1, TrxR2, Gpx1, LC3 $\beta$, PARP, TIA-1 (Santa Cruz Biotechnology, CA, USA), pAkt ${ }^{\text {ser473 }}$ (Cell Signaling Technology, MA, USA), $\beta$ -

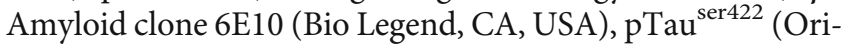
Gene Technologies, MD, USA), Rab5 (Lonza, SC, USA), CD9 (Life Technologies, CA, USA), CD81 (Thermo Fisher Scientific, MA, USA), Bcl-2 (Bio Source, CA, USA).

Secondary antibodies, used at 1:3000 dilution, were all from Thermo Fisher Scientific (Waltham, MA, USA).

2.12. Immunofluorescence and Confocal Microscopy. For immunofluorescence analysis, primary neurons seeded on coated coverslips were processed and confocal imaging was performed using a Nikon A1 confocal laser scanning microscope, as previously described [26].

Primary antibodies to detect $\beta$ Tubulin III (Millipore, CA, USA), pTau ${ }^{\text {ser422 }}$ (OriGene Technologies, MD, USA), and 6E10 (Bio Legend, CA, USA) were used following datasheet recommended dilutions. Alexa secondary antibodies (Thermo Fisher Scientific, Waltham, MA, USA) were used at $1: 200$ dilution.

The confocal serial sections were processed with ImageJ software to obtain three-dimensional projections. The image rendering was performed by Adobe Photoshop software.

For apoptosis detection, after 3 washes with $50 \mu$ l of binding buffer (10 mM HEPES, pH 7.5, containing $140 \mathrm{mM} \mathrm{NaCl}$, and $2.5 \mathrm{mM} \mathrm{CaCl}_{2}$ ), the specimen was incubated for 15 minutes with $50 \mu \mathrm{l}$ of double staining solution (binding buffer containing $0.25 \mu \mathrm{l}$ of annexin V-FITC and $0.25 \mu \mathrm{l}$ of propidium iodide (PI); BD Pharmingen ${ }^{\mathrm{TM}}$, Erembodegem, Belgium). Finally, the specimen was washed 5 times with $50 \mu \mathrm{l}$ of binding buffer, mounted with $15 \mu \mathrm{l}$ of binding buffer, and visualized under fluorescence microscopy [24].

2.13. Statistical Analysis. In vitro experiments were performed in triplicate. For quantitative comparisons, values were reported as mean \pm SEM based on triplicate analysis for each sample. To test the significance of observed differences among the study groups, one-way ANOVA with Bonferroni post hoc test or Student $t$ test (where only two samples were compared) were applied. A $p$ value $<0.05$ was considered to be statistically significant. FAD and FAD + EV samples were compared to WT sample and the ANOVA analysis was shown with asterisk over the column; the same analysis revealed that the comparison between FAD and $\mathrm{FAD}+\mathrm{EV}$ and the significativity was shown with additional asterisks over lines. Statistical analysis and plot layout were obtained by using GraphPad Prism ${ }^{\circledR}$ release 6.0 software.

\section{Results}

3.1. Morphological Characterization of Cultured Neurons Exposed to AFSC-EV. FAD neurons appeared unhealthy, if compared to WT neurons, since neurodegeneration in FAD neurons was prominent, as indicated by shrunken nuclear envelope (Figure 1(a) lower images) and neurite deterioration (Figure 1(a) upper images), as shown in graphs displaying number, length, and thickness (Figure 1(b)). The effect of 14 days EV treatment was to counteract the nuclear envelope modification and to avoid neurite loss, since the measures of neurite parameters were brought back similar to the WT ones. Similar results were obtained in all the experiments shown here below, despite individual variability due to AFSC samples obtained from different women.

3.2. ROS Modulation by AFSC-EV in FAD Neurons. The analysis of ROS content shown in Figure 2(a) revealed that FAD neurons displayed a higher ROS level compared to WT cells, as expected. Conversely, GSH is lower in FAD neurons, even though not significantly. However, the exposure to AFSC-EV reduced the ROS content, while allowed the increase in GSH level.

Then, we investigated the expression of proteins related to ROS modulation, and WB analysis (Figure 2(b)) demonstrated that antioxidant enzymes, such as SOD1, thioredoxin reductases TrxR1 and TrxR2, and glutathione peroxidase 1 (Gpx1), were all more present in FAD+EV neurons than in FAD cells. The comparison between FAD and WT did not show differences, excepted for TrxR1. The increase in TrxR1 expression in FAD neurons could be related to an intracellular defense against the ROS rise that we previously observed.

In parallel, the FAD neurons displayed a higher level of Nox4, a ROS producing enzyme constitutively active. Indeed, it does not need cytosolic subunits for activation, though they are able to modulate Nox 4 activity. This effect was reduced, at least in part, by the presence of EV. Meanwhile, no differences were observed for the expression of gp91phox, the typical subunit of Nox2, another NADPH oxidase expressed into the brain. Aside from phagocytic cells, including microglia, Nox2 is also found in endothelial cells and neurons [27].

Interestingly, the characterization of AFSC-EV revealed that all the samples, even though with different level of exosome markers (CD9, CD81 and Rab5), carried similar levels of SOD1 protein.

3.3. Effect of AFSC-EV on Apoptotic and Autophagic Pathways. Neuronal viability in FAD neurons was significantly decreased by $25 \%$ in DIV (days in vitro) 14 cultures, compared to WT neurons (Figure 3(a)). In parallel, the analysis of apoptosis by annexin $\mathrm{V}$ and propidium iodide (PI) demonstrated that the apoptotic pathway is involved, as expected (Figure 3(b)). However, the presence of EV significantly restored cell viability and reduced annexin $\mathrm{V}$ and $\mathrm{PI}$ staining (Figures 3(a) and 3(b)). In accordance with this result, our immunoblotting data further demonstrated an 

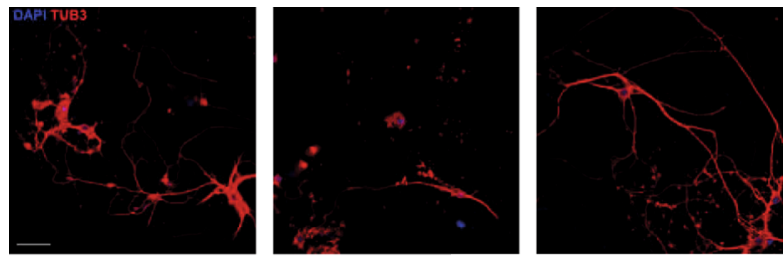

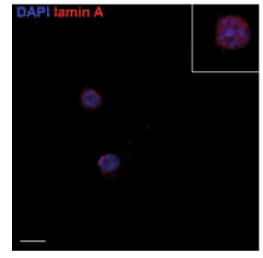

wt

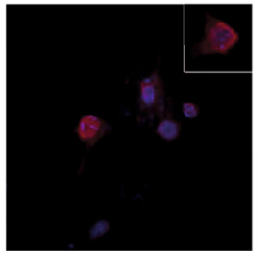

FAD

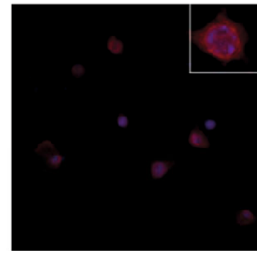

$\mathrm{FAD}+\mathrm{EV}$

(a)

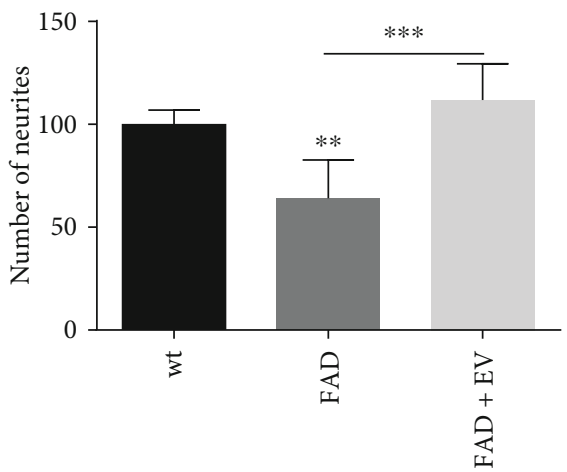

FIGURE 1: Effect of AFSC-EV supplementation on cell morphology of AD primary neurons in vitro. (a) Cells were incubated for 14 days with neurobasal medium 2\% B27 containing AFSC-EV replaced once a week. Representative images with DAPI (blue) and $\beta$ TubulinIII (red) or lamin A (red) signals of WT and FAD cells incubated or not with EV are shown. Scale bar $=10 \mu \mathrm{m}$. In white squares are shown representative doubled magnification images. (b) Mean measures in percentage \pm SEM of number, length, and diameter of neurites visualized in 10 fields for each condition are shown in graphs. ${ }^{*} p$ value $<0.05 ;{ }^{* *} p$ value $<0.01 ;{ }^{* * *} p$ value $<0.001$.

increased activation of Akt, a key signaling molecule for neuronal survival, indicated by the higher phosphorylation, with a concomitant activation of $\mathrm{Bcl}-2$, an anti-apoptotic marker, in FAD+EV neurons (Figure 3(c)). Moreover, the cleavage of PARP, significantly higher in FAD neurons, compared to WT, was reduced by the EV-treatment. These results suggest that the decreased cell viability associated with the activation of apoptotic pathway in FAD neurons could be contained by AFSC-EV.

In order to test the role of the PI3K/Akt pathway, we used wortmannin, selective and irreversible inhibitor of phosphatidylinositol 3-kinase (PI3K). The results on ROS and apoptosis (Supplementary Figure I) show that the inhibition of the PI3K/Akt pathway partially affects the extracellular vesicle modulation, suggesting its involvement in the EV efficacy.

Autophagic pathways were also modulated through AFSCEV content, as demonstrated by the increased levels of SIRT1, a NAD-dependent class III histone and nonhistone protein deacetylase, and LC3 $\beta$ protein. Both proteins are markers of autophagy, and their expression is altered during $\mathrm{AD}$ [28].

3.4. Reduction of AD Markers in the Presence of AFSC-EV. Finally we investigated the modulation of intracellular AD markers, by using the antibody $6 \mathrm{E} 10$, specific for human Amyloid precursor protein (APP), A $\beta$ oligomers [29], and molecules generated from cleavage of APP by secretases [30], and anti-Tau phosphorylated in Serine 422 [31], a pathological epitope and one of the markers of neurofibrillary degeneration: both are neuropathological hallmarks of Alzheimer's disease.

Our immunoblotting results demonstrated that levels of APP, A $\beta$ oligo, and $\mathrm{p}$-Tau ${ }^{\text {ser422 }}$ were reduced in EV-treated $\mathrm{AD}$ neurons (Figures 4(a) and 4(c)). These results were confirmed by immunofluorescence images shown in Figures 4(b) and $4(\mathrm{~d})$, where the signals of $6 \mathrm{E} 10$ and $\mathrm{p}$-Tau ${ }^{\text {ser } 422}$ dropped down in EV-samples.

Furthermore, the quantitative detection of secreted $\mathrm{A} \beta 42$ demonstrated the positive effect of AFSC-extracellular vesicle on FAD neurons, since the production of $\mathrm{A} \beta$ in $\mathrm{AD}$ neurons was decreased after treatment.

\section{Discussion}

In the last decades, stem cells have been in the spotlight as a promising candidate for regenerative medicine. Amongst these, mesenchymal stromal cells from the amniotic fluid (AFSCs) have been shown to favor tissue repair and 
ROS

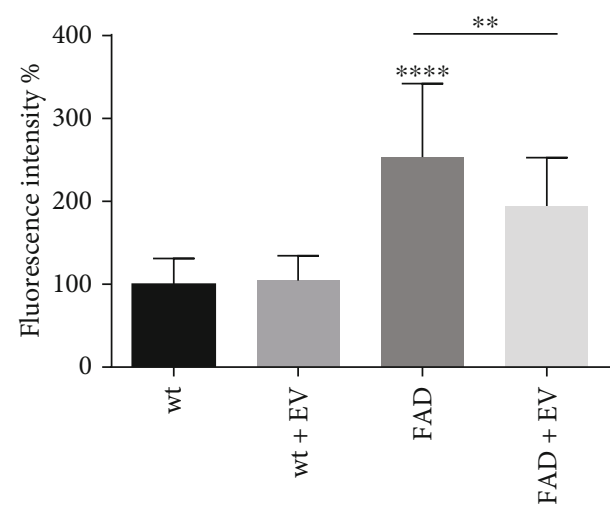

GSH

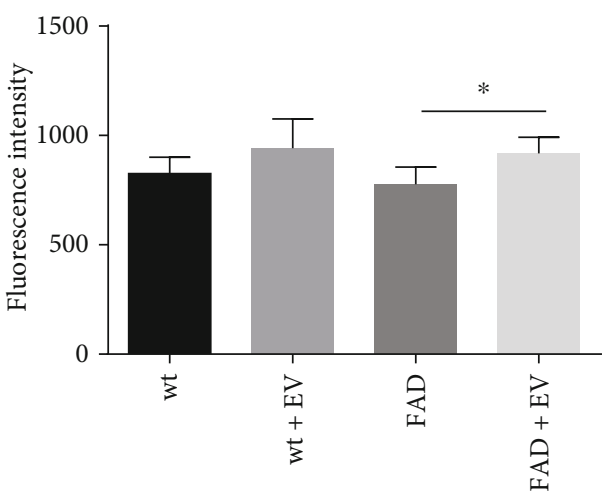

(a)
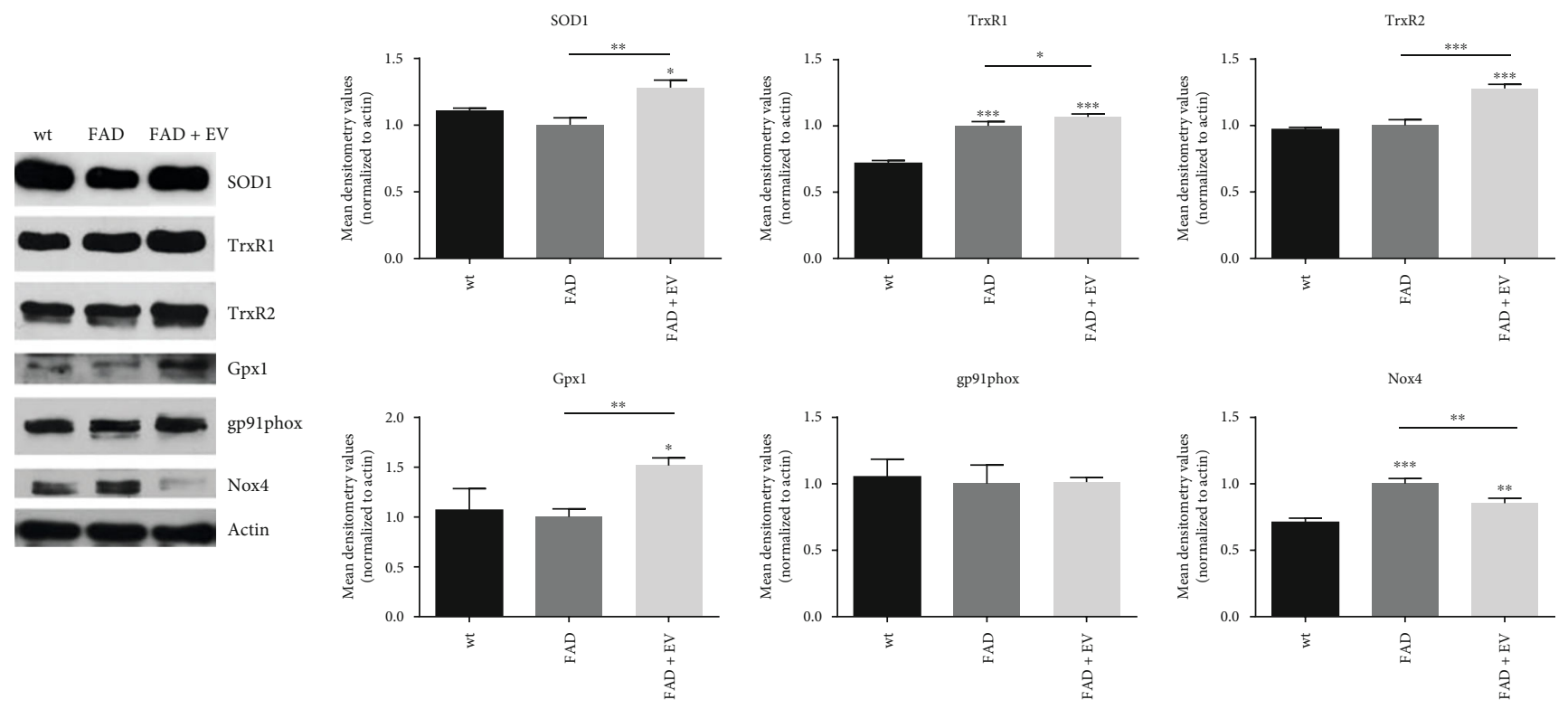

(b)
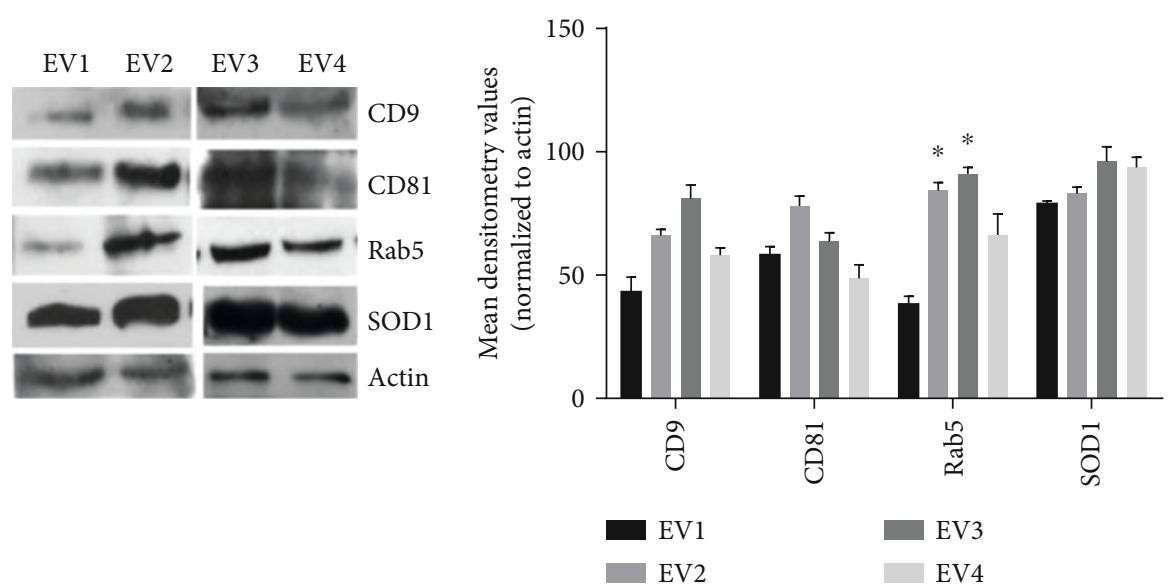

(c)

FIGURE 2: Effect of AFCS-EV supplementation on ROS modulation in AD primary neurons. (a) ROS and GSH content was measured with fluorescent probes, as described in Section 2.8, after 7 days of AFSC-EV exposure. ${ }^{*} p$ value $<0.05 ;{ }^{* *} p$ value $<0.01 ; * * * * p$ value $<0.0001$. (b) Western blot analysis of total lysate of WT, FAD cells treated or not with AFSC-EV, then revealed with the indicated primary antibodies. The graphs represent the mean \pm SEM of densitometric analysis of 3 experiments, normalized to actin values. ${ }^{*} p$ value $<0.05$; ${ }^{* *} p$ value $<0.01$; ${ }^{* * *} p$ value $<0.001$. (c) Western blot analysis of AFSC-extracellular vesicles derived from 4 donors, then revealed for CD9, CD81, and Rab5, as exosome markers, SOD1, and actin. The graph represents the mean \pm SEM of densitometric analysis of 3 experiments, normalized to actin values. $* p$ value $<0.05$. 


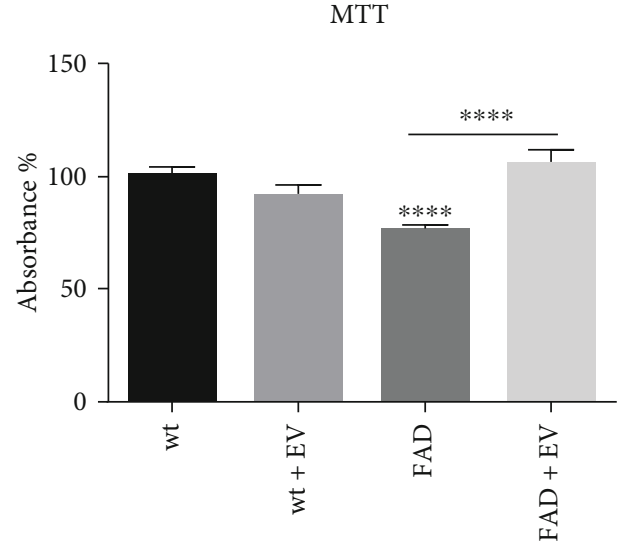

(a)

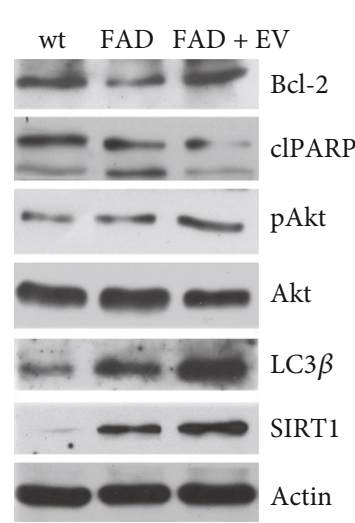

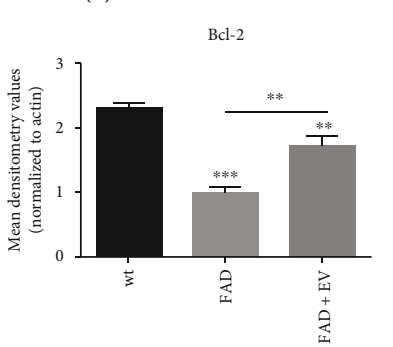

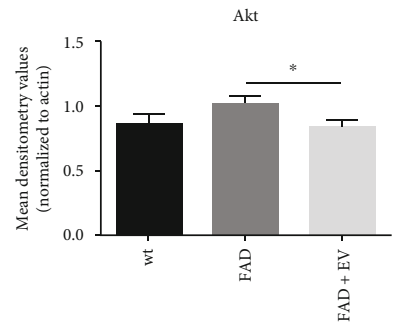

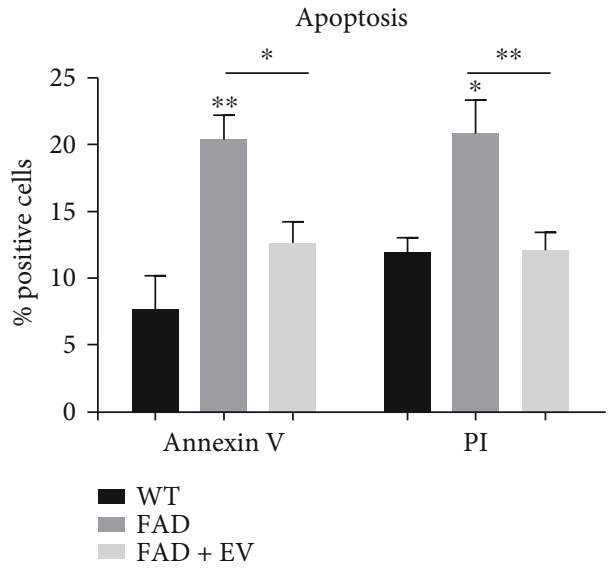

(b)
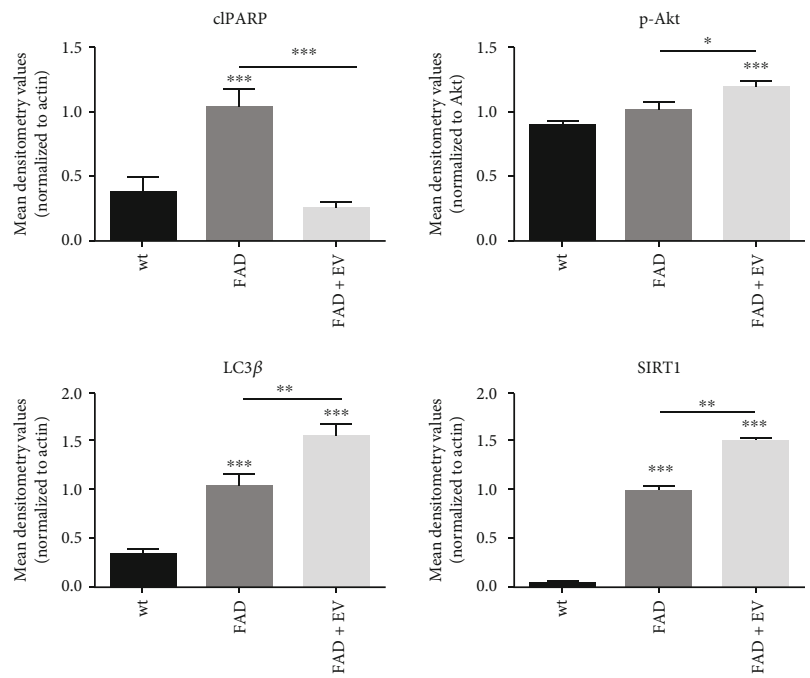

(c)

FIGURE 3: Effect of AFSC-EV supplementation on apoptotic and autophagic pathways of AD primary neurons in vitro. (a) Representative graph showing MTT viability of WT and FAD cells treated or not with AFSC-EV. ${ }^{* * * *} p$ value $<0.0001$. (b) Representative graph showing the percentage of positive cells to Annexin V/Propidium Iodide assay, as described in the 2.12 section. ${ }^{*} p$ value $<0.05$; ${ }^{* *} p$ value $<0.01$. (c) Western blot analysis of total lysate of WT, FAD cells treated or not with AFSC-EV, then revealed with anti-Bcl-2, anti-PARP, antipAkt, anti-LC $3 \beta$, and anti-SIRT1 antibodies. The graphs represent the mean \pm SEM of densitometric analysis of 3 experiments, normalized to actin values. ${ }^{*} p$ value $<0.05 ;{ }^{* *} p$ value $<0.01 ;{ }^{* * *} p$ value $<0.001$.

regeneration after transplantation in animal models of inflammatory-based diseases. The benefits of transplanted amniotic cells were observed despite cell engraftment in injured tissue, thus suggesting that these cells produce bioactive factors able to mediate the above-mentioned effects through paracrine signaling [32]. Stem cells secrete various molecules such as growth factors and extracellular vesicles [33], able to modulate oxidative stress. Since endogenous and microenvironmental oxidative stress may be a pivotal factor exacerbating pathways driving to neuronal loss in $\mathrm{AD}$ [34], here, we explored the effects of a suspension enriched in exosomes, derived from AFSCs in culture, on the viability of neurons obtained from AD mice, and demonstrated that the redox state is deeply modified by such exposure.

We are aware that the used isolation technique could give possible differences compared to ultracentrifugation and SEC protocols: indeed, it has been demonstrated that this kit gave the highest yield but the preparation showed broader sizedistribution likely due to microvesicle co-precipitation and had the least dispersion stability [35]. Therefore, in order to compare the efficacy of these extracellular vesicles, obtained with this commercial kit, and the other part of secretome, namely, the supernatant derived from such isolation process $(-E V)$, we performed viability and ROS analyses on the recognized in vitro AD model, SH-SY $5 Y$ exposed to $\mathrm{A} \beta$, treated with $+\mathrm{EV}$ or $-\mathrm{EV}$. The results, shown in supplementary Figure II, confirmed our previous observations on other cell types (human lymphocytes) [15]: actually, the presence of EV showed an increase in the viability of $\mathrm{A} \beta$-treated cells and a decrease in ROS content, but - EV did not exert any modulation, supporting the validity of the extracellular vesicle effect on neurons obtained from $\mathrm{AD}$ mice. 


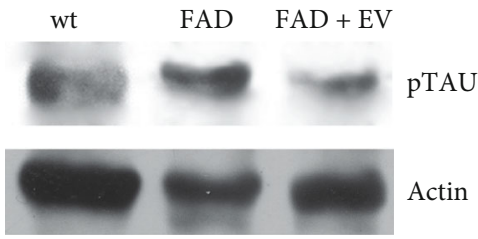

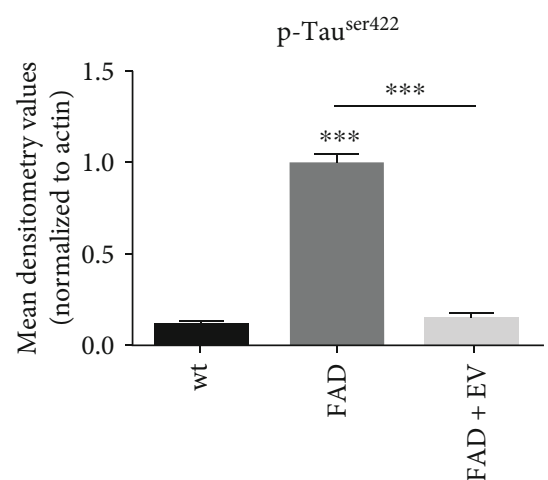

(a)
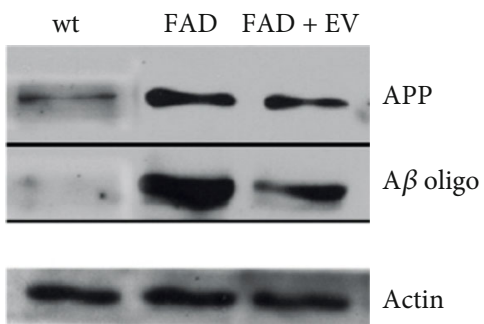

APP $100 \mathrm{kDa}$

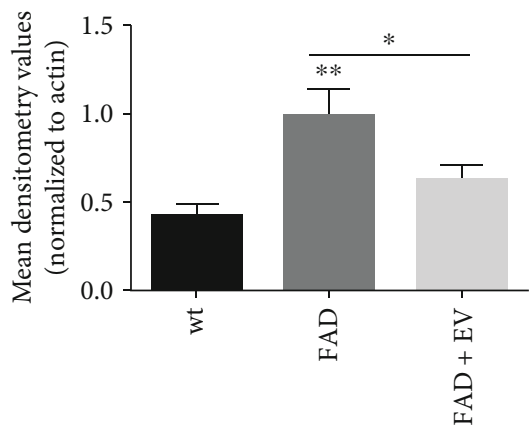

$\mathrm{A} \beta$ oligo $16 \mathrm{kDa}$

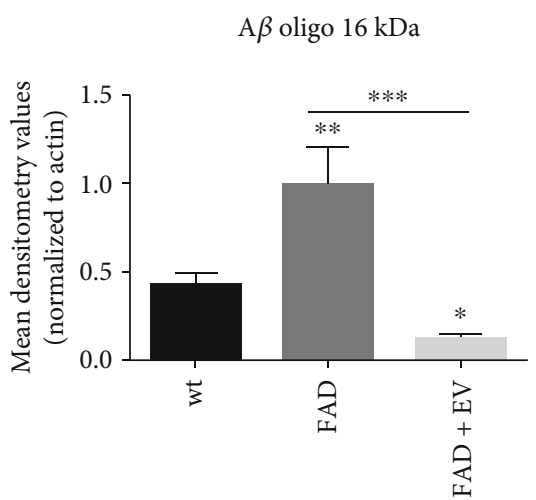

(c)

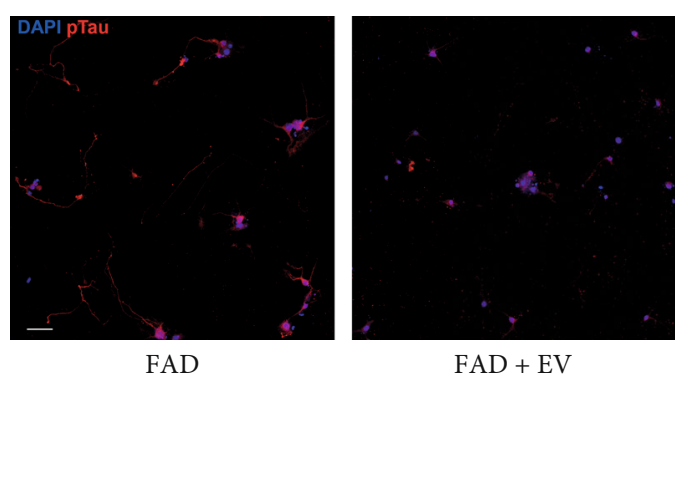

(b)

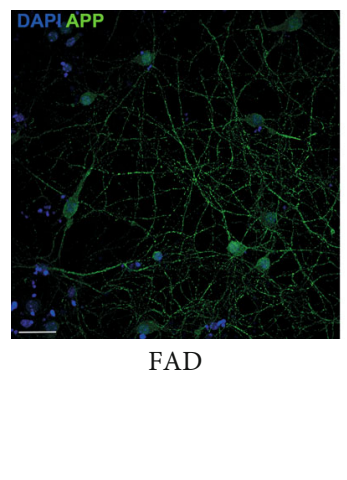

(d)

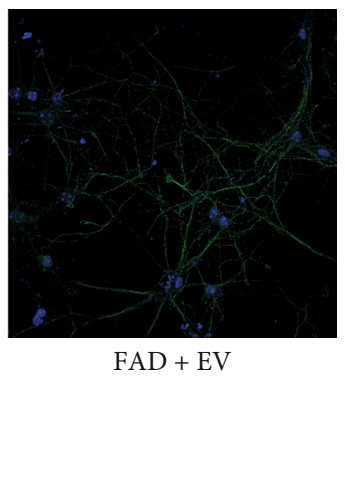

Figure 4: Continued. 


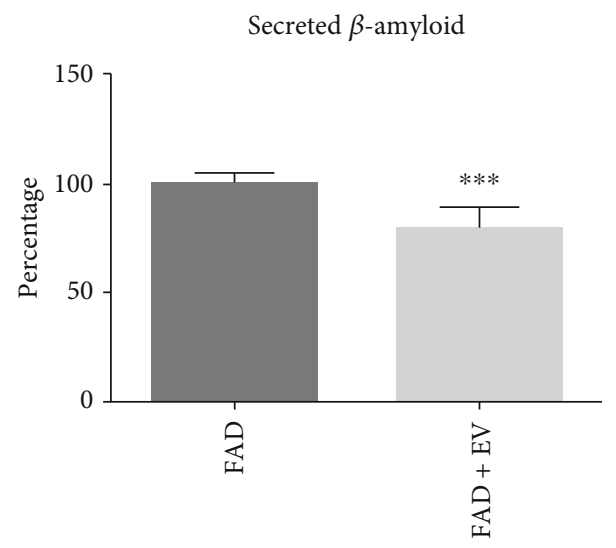

(e)

Figure 4: Effect of AFSC-EV supplementation on AD markers of AD primary neurons in vitro. (a) Western blot analysis of total lysate of WT and FAD cells treated or not with AFSC-EV, then revealed with anti-p-Tau ${ }^{\text {ser422 }}$ antibody. The graph represents the mean \pm SEM of densitometric analysis of 3 experiments, normalized to actin values. ${ }^{* * *} p$ value $<0.001$. (b) Representative images showing DAPI (blue) and p-Tau ${ }^{\text {ser422 }}$ (red) signals of FAD cells incubated or not with EV. Scale bar $=10 \mu \mathrm{m}$. (c) Western blot analysis of total lysate of WT, FAD cells treated or not with AFSC-EV, then revealed with $6 \mathrm{E} 10$ antibody. APP $(100 \mathrm{kDa})$ and A $\beta$ oligo $(16 \mathrm{kDa})$ bands, with $6 \mathrm{E} 10$, are shown. The graphs represent the mean \pm SEM of densitometric analysis of 3 experiments, normalized to actin values. $* p$ value $<0.05$; ${ }^{* *} p$ value $<0.01 ; * * * \mathrm{p}$ value $<0.001$. (d) Representative images with DAPI (blue) and APP (green) signals of FAD cells incubated or not with AFSC-EV are shown. Scale bar $=10 \mu \mathrm{m}$. (e) Percentage of secreted $\beta$-amyloid of FAD cells treated or not with AFSC-EV for 7 days. These data are obtained by measuring the A $\beta 42$ levels via ELISA as described in Section 2.9. ${ }^{* * *} p$ value $<0.001$.

Such modulation, described above, occurred in parallel with a decrease in the accumulation of extracellular amyloid- $\beta$. Accordingly, the key biochemical change in $\mathrm{AD}$ is the modification by the ROS of $A \beta$ into toxic products, which progressively aggregate into senile plaques promoting apoptosis [36]. Indeed, considerable evidence now indicates that soluble $A \beta$ oligomers, monomers, and protofibrils, rather than amyloid deposits, are the main toxic agents in $\mathrm{AD}$ [37]. Consistently, we observed a decrease in the APP and $\mathrm{A} \beta$ oligomers intracellular content as well.

In line with this consideration, we noticed that the rescue of neurons viability exposed to AFSC-EV is accompanied by a decline in apoptotic markers. Moreover, morphological aspects, deriving from neurotoxicity, such as neurite and nuclear envelope modifications, were prevented. Typical nuclear abnormalities consisting of altered nuclear envelope/lamina structure were observed in several age-related diseases [38] and in AD as well [39].

Other $\mathrm{AD}$ features were also taken into consideration, such as impairment of autophagy and Tau phosphorylation, since both of them are, to a certain extent, linked to redox unbalance. Indeed, oxidative stress also supports a process of progressive failure of autophagy in neurons and promotes Tau phosphorylation, then causing impaired memory deficit [1]. Moreover, growing evidence suggests that APP processing and $\mathrm{A} \beta$ release are upstream of Tau pathology. Tau hyperphosphorylation is implicated in autophagy dysfunction, and increased levels of lysosomal protease occur in $\mathrm{AD}$ patients [40]. Indeed, we noticed that $\mathrm{FAD}$ samples showed a higher level of LC3B, the protein involved in the formation of autophagosomal vacuoles, an event probably due to an early cellular response to the need to eliminate protein aggregates, which remains insufficient to counteract the progress of the pathology. More interestingly, we observed that the presence of extracellular vesicle treatment induced a further increase in the autophagic marker LC3B. EV administration positively regulated SIRT1 expression as well. This effect supports the proposed role of extracellular vesicles in regulating ROS levels and autophagy, since sirtuins are antioxidant and antiapoptotic and crucial mediators for lysosomal autophagy regulation, which plays a pivotal role in the $\mathrm{AD}[41]$.

Moreover, ROS has been shown to regulate autophagy through several signaling pathways such as PI3K/Akt, AMPK. These pathways appear to be crucial in $\mathrm{AD}$ since related to the Tau protein hyperphosphorylation. In addition, the PI3K/Akt pathway has been shown to play a critical role in the neuroprotection and inhibiting apoptosis via the enhancing expression of the SODs [42]. Similarly, here, we demonstrated that the presence of extracellular vesicles favored the activation of Akt, being this protein more phosphorylated after EV-exposure. Moreover, in case of inhibition of the PI3K/Akt pathway, the extracellular vesicle modulation ROS and apoptosis was affected, suggesting its partial involvement in the EV efficacy. All these data are in line with the observations carried out on a model of $\mathrm{AD}$, generated by treating in vitro SH-SY 5Y cells (a human neuroblastoma cell line) with $\mathrm{A} \beta$, where the authors showed that BM-MSCs stimulated autophagy in diseased neurons exposed to toxic protein aggregates and the enhancement of aggregate degradation, thus increasing neuronal survival [43].

Interestingly, we then confirmed that the treatment with AFSC-extracellular vesicles prevented the phosphorylation of Tau protein at serine 422 , the typical site of phosphorylation occurring in $\mathrm{AD}$ [31], suggesting that the redox regulation by extracellular vesicles may affect the whole $\mathrm{AD}$ pathogenesis. This is consistent with the hypothesis that increased ROS 
production may have an integral role in the development of sporadic AD prior to the appearance of amyloid and Tau pathology [44].

The mechanisms proposed by de Godoy et al. [14] to explain, at least in part, neuroprotection by MSC-EVs pertains to the content in antioxidant enzymes and in antiinflammatory and/or trophic molecules. The authors demonstrated that EVs secreted by MSCs contain and carry endogenous catalase that endows EVs of ROS scavenging activity. Similarly, we clearly observed that SOD1 is contained into AFSC-extracellular vesicles. SOD1 presence might be one of the mechanisms of protection exerted by extracellular vesicles in neurodegeneration, avoiding an excess of reactive oxygen species. A decrease in reduced glutathione (GSH) causes excess in ROS production leading to oxidative stress, thus favoring $\mathrm{AD}$ pathogenesis [45]. Here, we demonstrated that exposure to AFSC-EV induced a significant rise in glutathione peroxidase (Gpx) enzyme; thus, it is not surprising to see that EVtreatment increased GSH levels in FAD neurons. These samples showed a slightly minor content of GSH, compared to WT, in accordance with the data obtained by Resende et al. in the 3xTg-AD mice, an AD mouse model, where decreased levels of GSH were observed [46]. A similar trend, even if not statistically significant, also occurred in WT cells, when treated with EV. This slight difference between WT and FAD neurons in GSH levels after 7 days in culture is likely to be due to a cellular defense that can be noticed in the expression increase of the antioxidant enzyme thioredoxin reductase 1 (TrxR1). Moreover, both TrxR1 and TrxR2 presence surged after EV-exposure, contributing with SOD1 and Gpx to the ROS decrease observed in these samples. This complex redox balance is also influenced by the presence of prooxidant enzymes, namely NADPH oxidases. In this experimental condition, Nox4, the isoform constitutively active, showed a higher content in FAD samples, being reduced, at least partially, after EV-treatment. Regarding gp91phox, the specific subunit of Nox2, no differences could be observed, perhaps because the activation of this isoform derives mostly from a regulating subunit interaction [27].

The analysis of our data demonstrated that extracellular vesicles derived from stem cells have a direct effect on neurons affected by $\mathrm{AD}$, modulating ROS content. Meanwhile, most of the literature shows an indirect therapeutic potential, underlining a regulation of neuroinflammation reducing microglial activation [47] [48] [49].

We have previously demonstrated that AFSCextracellular vesicles contain anti-inflammatory molecules, namely, HFG, TGF $\beta$, and pentraxin 3 [15] that showed a therapeutic effect on osteoarthritis [16]. Even in this context, pentraxin 3, that is, a protein regulator of angiogenesis and neurogenesis with direct involvement in neuroinflammation in acute phases [50], could have a therapeutic role. The positive effect of MSC secretome on both fronts, namely, neurons and microglial cells, could be the winning key that justifies the encouraging results obtained on $\mathrm{AD}$ features by using MSCs in vivo. For example, the transplantation of human umbilical cord blood and adipose-derived MSC, into the hippocampus of mouse $\mathrm{AD}$ models, reduced $\mathrm{A} \beta$ plaques, increased endogenous adult neurogenesis and synaptic activity, and enhanced cognitive function [51] [52].

\section{Conclusions}

In conclusion, in this study, we focused our attention on extracellular vesicles in preventing the disease phenotypes of the only neurons in culture. We employed cells deriving from $5 x F A D$ mice [53], a more complete animal model of $\mathrm{AD}$, if compared to Tg2576 from which primary neurons were obtained in the study by Lee et al. [54]. Indeed, Tg2576 is a mouse model carrying a single human amyloid precursor protein mutation (APPswe) [55]. However, in our model, the exposure of MSC extracellular vesicles ameliorated the progression of $\mathrm{A} \beta$-induced neuronal death and $\mathrm{AD}$ as well, supporting the idea proposed by Lee et al. that extracellular vesicles, derived in that case from adipose tissue, could exert disease-modulating effects [54]. Furthermore, here, we clearly demonstrated a ROS regulation involvement in extracellular vesicle therapeutic effect in neurodegenerative diseases, such as AD.

\section{Abbreviations}

\section{AFSCs: $\quad$ Amniotic fluid stem cells}

BSA: $\quad$ Bovine serum albumin

DCFH-DA: Dichlorodihydrofluorescein diacetate

DAPI: $\quad 4^{\prime}$,6-diamidino-2-phenylindole

EDTA: Ethylenediaminetetraacetic acid

EV: $\quad$ Extracellular vesicles

PBS: $\quad$ Phosphate buffered saline

HEPES: $\quad$ 4-(2-hydroxyethyl)-1-piperazineethanesulfonic acid

MCB: $\quad$ Monochlorobimane

SDS: $\quad$ Sodium dodecyl sulfate

WB: Western blot.

\section{Data Availability}

Previously reported electron microscopy data were used to support this study and are available at doi:10.1002/biof.1407. These prior studies (and datasets) are cited at relevant places within the text as references [15].

\section{Ethical Approval}

An informed consent allowing the use of clinical data and biological samples for the specified research purpose (protocol 360/2017 dated 12.15.2017) was signed by all infertile couples before treatment and collected by the Unit of Obstetrics \& Gynecology, Policlinico of Modena (Italy).

\section{Conflicts of Interest}

All the authors report no conflict of interest since nobody has commercial associations that might create a conflict of interest in connection with submitted manuscripts. 


\section{Authors' Contributions}

MG, PhD student, performed extracellular vesicle extractions; MZ, lab technician, isolated neurons; $\mathrm{FB}$, lab technician, performed ELISA analysis; $\mathrm{EV}, \mathrm{PhD}$, and $\mathrm{DG}, \mathrm{PhD}$, are responsible for colonies of $5 \mathrm{xFAD}$ mice; $\mathrm{AO}, \mathrm{PhD}$, performed western blot analysis; $\mathrm{EB}, \mathrm{MD}$, amniotic fluids and informed consent collection; TM, PI of the group, is responsible of the design of the work, acquisition, and interpretation of data and drafting the manuscript. All authors read and approved the final manuscript.

\section{Acknowledgments}

This work was supported by the grant from FAR (Fondo di Ateneo per la Ricerca) and Fondazione Cassa di Risparmio di Carpi. We are grateful to Dr Antonietta Vilella for genotyping mice service.

\section{Supplementary Materials}

Supplementary Figure I: effect of Inhibition of P13K/Akt on apoptosis and ROS of FAD neurons. Supplementary Figure II: effect of hAFSC secretome on AB-induced neuron toxicity and ROS level. (Supplementary Materials)

\section{References}

[1] Z. Liu, T. Zhou, A. C. Ziegler, P. Dimitrion, and L. Zuo, "Oxidative stress in neurodegenerative diseases: from molecular mechanisms to clinical applications," Oxidative Medicine and Cellular Longevity, vol. 2017, 11 pages, 2017.

[2] H. W. Querfurth and F. M. LaFerla, "Alzheimer's disease," New England Journal of Medicine, vol. 362, no. 4, pp. 329344, 2010.

[3] E. Ferreiro, C. R. Oliveira, and C. M. F. Pereira, "The release of calcium from the endoplasmic reticulum induced by amyloidbeta and prion peptides activates the mitochondrial apoptotic pathway," Neurobiology of Disease, vol. 30, no. 3, pp. 331-342, 2008.

[4] P. B. Shelat, M. Chalimoniuk, J. H. Wang et al., "Amyloid beta peptide and NMDA induce ROS from NADPH oxidase and AA release from cytosolic phospholipase A2 in cortical neurons," Journal of Neurochemistry, vol. 106, no. 1, pp. 45-55, 2008.

[5] D. Giuliani, A. Ottani, D. Zaffe et al., "Hydrogen sulfide slows down progression of experimental Alzheimer's disease by targeting multiple pathophysiological mechanisms," Neurobiology of Learning and Memory, vol. 104, pp. 82-91, 2013.

[6] D. Giuliani, A. Bitto, M. Galantucci et al., "Melanocortins protect against progression of Alzheimer's disease in tripletransgenic mice by targeting multiple pathophysiological pathways," Neurobiology of Aging, vol. 35, no. 3, pp. 537-547, 2014.

[7] P. I. Moreira, A. I. Duarte, M. S. Santos, A. C. Rego, and C. R. Oliveira, "An integrative view of the role of oxidative stress, mitochondria and insulin in Alzheimer's disease," Journal of Alzheimer's Disease, vol. 16, no. 4, pp. 741-761, 2009.

[8] I. Ferrer, T. Gomez-Isla, B. Puig et al., "Current advances on different kinases involved in tau phosphorylation, and implications in Alzheimers disease and tauopathies," Current Alzheimer Research, vol. 2, no. 1, pp. 3-18, 2005.
[9] L. Zuo, T. Zhou, B. K. Pannell, A. C. Ziegler, and T. M. Best, "Biological and physiological role of reactive oxygen species the good, the bad and the ugly," Acta Physiologica, vol. 214, no. 3, pp. 329-348, 2015.

[10] K. Bisht, K. Sharma, and M. È. Tremblay, "Chronic stress as a risk factor for Alzheimer's disease: roles of microglia-mediated synaptic remodeling, inflammation, and oxidative stress," Neurobiology of Stress, vol. 9, pp. 9-21, 2018.

[11] J. Teixeira, T. Silva, P. Andrade, and F. Borges, "Alzheimer's disease and antioxidant therapy: how long how far?," Current Medicinal Chemistry, vol. 20, no. 24, pp. 2939-2952, 2013.

[12] C. A. Elia, M. Losurdo, M. L. Malosio, and S. Coco, "Extracellular vesicles from mesenchymal stem cells exert pleiotropic effects on amyloid- $\beta$, inflammation, and regeneration: a spark of hope for Alzheimer's disease from tiny structures?," BioEssays, vol. 41, no. 4, article e1800199, 2019.

[13] T. Katsuda, R. Tsuchiya, N. Kosaka et al., "Human adipose tissue-derived mesenchymal stem cells secrete functional neprilysin-bound exosomes," Scientific Reports, vol. 3, no. 1, p. 1197, 2013.

[14] M. A. de Godoy, L. M. Saraiva, L. R. P. de Carvalho et al., "Mesenchymal stem cells and cell-derived extracellular vesicles protect hippocampal neurons from oxidative stress and synapse damage induced by amyloid- $\beta$ oligomers," Journal of Biological Chemistry, vol. 293, no. 6, pp. 1957-1975, 2018.

[15] F. Beretti, M. Zavatti, F. Casciaro et al., "Amniotic fluid stem cell exosomes: therapeutic perspective," BioFactors, vol. 44, no. 2, pp. 158-167, 2018.

[16] M. Zavatti, F. Beretti, F. Casciaro, E. Bertucci, and T. Maraldi, "Comparison of the therapeutic effect of amniotic fluid stem cells and their exosomes on monoiodoacetate-induced animal model of osteoarthritis," BioFactors, vol. 46, no. 1, pp. 106117, 2019.

[17] P. Maiti, L. Paladugu, and G. L. Dunbar, "Solid lipid curcumin particles provide greater anti-amyloid, anti-inflammatory and neuroprotective effects than curcumin in the $5 \mathrm{xFAD}$ mouse model of Alzheimer's disease," BMC Neuroscience, vol. 19, no. 1, p. 7, 2018.

[18] A. Kaminari, N. Giannakas, A. Tzinia, and E. C. Tsilibary, "Overexpression of matrix metalloproteinase-9 (MMP-9) rescues insulin-mediated impairment in the 5XFAD model of Alzheimer's disease," Scientific Reports, vol. 7, no. 1, p. 683, 2017.

[19] T. Maraldi, L. Bertoni, M. Riccio et al., "Human amniotic fluid stem cells: neural differentiation in vitro and in vivo," Cell and Tissue Research, vol. 357, no. 1, pp. 1-13, 2014.

[20] V. A. Baldassarro, A. Marchesini, L. Giardino, and L. Calza, "Vulnerability of primary neurons derived from Tg2576 Alzheimer mice to oxygen and glucose deprivation: role of intraneuronal amyloid- $\beta$ accumulation and astrocytes," DMM Disease Models and Mechanisms, vol. 10, no. 5, pp. 671-678, 2017.

[21] V. Marassi, F. Beretti, B. Roda et al., "A new approach for the separation, characterization and testing of potential prionoid protein aggregates through hollow-fiber flow field-flow fractionation and multi-angle light scattering," Analytica Chimica Acta, vol. 1087, pp. 121-130, 2019.

[22] P. Marrazzo, C. Angeloni, M. Freschi et al., "Combination of epigallocatechin gallate and sulforaphane counteracts in vitro oxidative stress and delays stemness loss of amniotic fluid stem cells," Oxidative Medicine and Cellular Longevity, vol. 2018, Article ID 5263985, 13 pages, 2018. 
[23] T. Maraldi, M. Riccio, L. Zambonin, M. Vinceti, A. De Pol, and G. Hakim, "Low levels of selenium compounds are selectively toxic for a human neuron cell line through ROS/RNS increase and apoptotic process activation," Neurotoxicology, vol. 32, no. 2, pp. 180-187, 2011.

[24] T. Maraldi, F. Beretti, M. Guida, M. Zavatti, and A. De Pol, "Role of hepatocyte growth factor in the immunomodulation potential of amniotic fluid stem cells," Stem Cells Translational Medicine, vol. 4, no. 6, pp. 539-547, 2015.

[25] M. Zavatti, E. Resca, L. Bertoni et al., "Ferutinin promotes proliferation and osteoblastic differentiation in human amniotic fluid and dental pulp stem cells," Life Sciences, vol. 92, no. 20-21, pp. 993-1003, 2013.

[26] M. Guida, T. Maraldi, E. Resca et al., "Inhibition of nuclear Nox 4 activity by plumbagin: effect on proliferative capacity in human amniotic stem cells," Oxidative Medicine and Cellular Longevity, vol. 2013, 12 pages, 2013.

[27] R. Rastogi, X. Geng, F. Li, and Y. Ding, "NOX activation by subunit interaction and underlying mechanisms in disease," Frontiers in Cellular Neuroscience, vol. 10, p. 301, 2017.

[28] S. Singh, A. K. Singh, G. Garg, and S. I. Rizvi, "Fisetin as a caloric restriction mimetic protects rat brain against aging induced oxidative stress, apoptosis and neurodegeneration," Life Sciences, vol. 193, pp. 171-179, 2018.

[29] Y. Zhu, H. Hou, K. Rezai-Zadeh et al., "CD45 deficiency drives amyloid- $\beta$ peptide oligomers and neuronal loss in alzheimer's disease mice," Journal of Neuroscience, vol. 31, no. 4, pp. 13551365, 2011.

[30] B. P. Imbimbo and M. Watling, "Investigational BACE inhibitors for the treatment of Alzheimer's disease," Expert Opinion on Investigational Drugs, vol. 28, no. 11, pp. 967-975, 2019.

[31] J. Götz, F. Chen, J. Van Dorpe, and R. M. Nitsch, "Formation of neurofibrillary tangles in P301L tau transgenic mice induced by Abeta 42 fibrils," Science, vol. 293, no. 5534, pp. 1491-1495, 2001.

[32] C. Balbi and S. Bollini, "Fetal and perinatal stem cells in cardiac regeneration: moving forward to the paracrine era," Placenta, vol. 59, pp. 96-106, 2017.

[33] H. Valadi, K. Ekström, A. Bossios, M. Sjöstrand, J. J. Lee, and J. O. Lötvall, "Exosome-mediated transfer of mRNAs and microRNAs is a novel mechanism of genetic exchange between cells," Nature Cell Biology, vol. 9, no. 6, pp. 654-659, 2007.

[34] E. Lévy, N. El Banna, D. Baïlle et al., "Causative links between protein aggregation and oxidative stress: a review," International Journal of Molecular Sciences, vol. 20, no. 16, p. 3896, 2019.

[35] G. K. Patel, M. A. Khan, H. Zubair et al., "Comparative analysis of exosome isolation methods using culture supernatant for optimum yield, purity and downstream applications," Scientific Reports, vol. 9, 2019.

[36] S. Ribarič, "Peptides as potential therapeutics for Alzheimer's disease," Molecules, vol. 23, no. 2, p. 283, 2018.

[37] M. Verma, A. Vats, and V. Taneja, "Toxic species in amyloid disorders: oligomers or mature fibrils," Annals of Indian Academy of Neurology, vol. 18, no. 2, pp. 138-145, 2015.

[38] G. Lattanzi, S. Marmiroli, A. Facchini, and N. M. Maraldi, "Nuclear damages and oxidative stress: new perspectives for laminopathies," European Journal of Histochemistry, vol. 56, no. 4, article e45, p. 45, 2012.

[39] B. Frost, "Alzheimer's disease: an acquired neurodegenerative laminopathy,” Nucleus, vol. 7, no. 3, pp. 275-283, 2016.
[40] Z. Liu, T. Li, P. Li et al., "The ambiguous relationship of oxidative stress, tau hyperphosphorylation, and autophagy dysfunction in Alzheimer's disease," Oxidative Medicine and Cellular Longevity, vol. 2015, Article ID 352723, 12 pages, 2015.

[41] H. Çelik, H. Karahan, and P. Kelicen-Uğur, "Effect of atorvastatin on A $\beta 1-42$-induced alteration of SESN2, SIRT1, LC3II and TPP1 protein expressions in neuronal cell cultures," Journal of Pharmacy and Pharmacology, vol. 72, no. 3, pp. 424436, 2019.

[42] S. Matsuda, Y. Nakagawa, A. Tsuji, Y. Kitagishi, A. Nakanishi, and T. Murai, "Implications of PI3K/AKT/PTEN signaling on superoxide dismutases expression and in the pathogenesis of Alzheimer's disease," Diseases, vol. 6, no. 2, p. 28, 2018.

[43] J. Y. Shin, H. J. Park, H. N. Kim et al., "Mesenchymal stem cells enhance autophagy and increase $\beta$-amyloid clearance in Alzheimer disease models," Autophagy, vol. 10, no. 1, pp. 32-44, 2014.

[44] J. H. Birnbaum, D. Wanner, A. F. Gietl et al., "Oxidative stress and altered mitochondrial protein expression in the absence of amyloid- $\beta$ and tau pathology in iPSC-derived neurons from sporadic Alzheimer's disease patients," Stem Cell Research, vol. 27, pp. 121-130, 2018.

[45] G. Cenini, A. Lloret, and R. Cascella, "Oxidative stress in neurodegenerative diseases: from a mitochondrial point of view," Oxidative Medicine and Cellular Longevity, vol. 2019, Article ID 2105607, 18 pages, 2019.

[46] R. Resende, P. I. Moreira, T. Proença et al., "Brain oxidative stress in a triple-transgenic mouse model of Alzheimer disease," Free Radical Biology \& Medicine, vol. 44, no. 12, pp. 2051-2057, 2008.

[47] E. Bagyinszky, V. Van Giau, K. Shim, K. Suk, S. S. A. An, and S. Y. Kim, "Role of inflammatory molecules in the Alzheimer's disease progression and diagnosis," Journal of the Neurological Sciences, vol. 376, pp. 242-254, 2017.

[48] H. Yang, Z. Xie, L. Wei et al., "Human umbilical cord mesenchymal stem cell-derived neuron-like cells rescue memory deficits and reduce amyloid-beta deposition in an A $\beta \mathrm{PP} / \mathrm{PS} 1$ transgenic mouse model," Stem Cell Research \& Therapy, vol. 4, no. 4, p. 76, 2013.

[49] H. M. Yun, H. S. Kim, K. R. Park et al., "Placenta-derived mesenchymal stem cells improve memory dysfunction in an A $\beta 1$ 42-infused mouse model of Alzheimer's disease," Cell Death and Disease, vol. 4, no. 12, p. e958, 2013.

[50] K. Ummenthum, L. A. N. Peferoen, A. Finardi et al., "Pentraxin-3 is upregulated in the central nervous system during MS and EAE, but does not modulate experimental neurological disease," European Journal of Immunology, vol. 46, no. 3, pp. 701-711, 2016.

[51] D. H. Kim, D. Lee, E. H. Chang et al., "GDF-15 secreted from human umbilical cord blood mesenchymal stem cells delivered through the cerebrospinal fluid promotes hippocampal neurogenesis and synaptic activity in an Alzheimer's disease model," Stem Cells and Development, vol. 24, no. 20, pp. 2378-2390, 2015.

[52] Y. Yan, T. Ma, K. Gong, Q. Ao, X. Zhang, and Y. Gong, “Adipose-derived mesenchymal stem cell transplantation promotes adult neurogenesis in the brains of Alzheimer's disease mice," Neural Regeneration Research, vol. 9, no. 8, pp. 798-805, 2014.

[53] M. S. Song, C. R. Learman, K. C. Ahn et al., "In vitro validation of effects of BDNF-expressing mesenchymal stem cells on neurodegeneration in primary cultured neurons of APP/PS1 mice," Neuroscience, vol. 307, pp. 37-50, 2015. 
[54] M. Lee, J. J. Ban, S. Yang, W. Im, and M. Kim, "The exosome of adipose-derived stem cells reduces $\beta$-amyloid pathology and apoptosis of neuronal cells derived from the transgenic mouse model of Alzheimer's disease," Brain Research, vol. 1691, pp. 87-93, 2018.

[55] K. Hsiao, P. Chapman, S. Nilsen et al., "Correlative memory deficits, $\mathrm{A} \beta$ elevation, and amyloid plaques in transgenic mice," Science, vol. 274, no. 5284, pp. 99-103, 1996. 